\title{
The butterfly
}

Cite as: CMAJ 2021 January 4;193:E27-8. doi: 10.1503/cmaj.202094

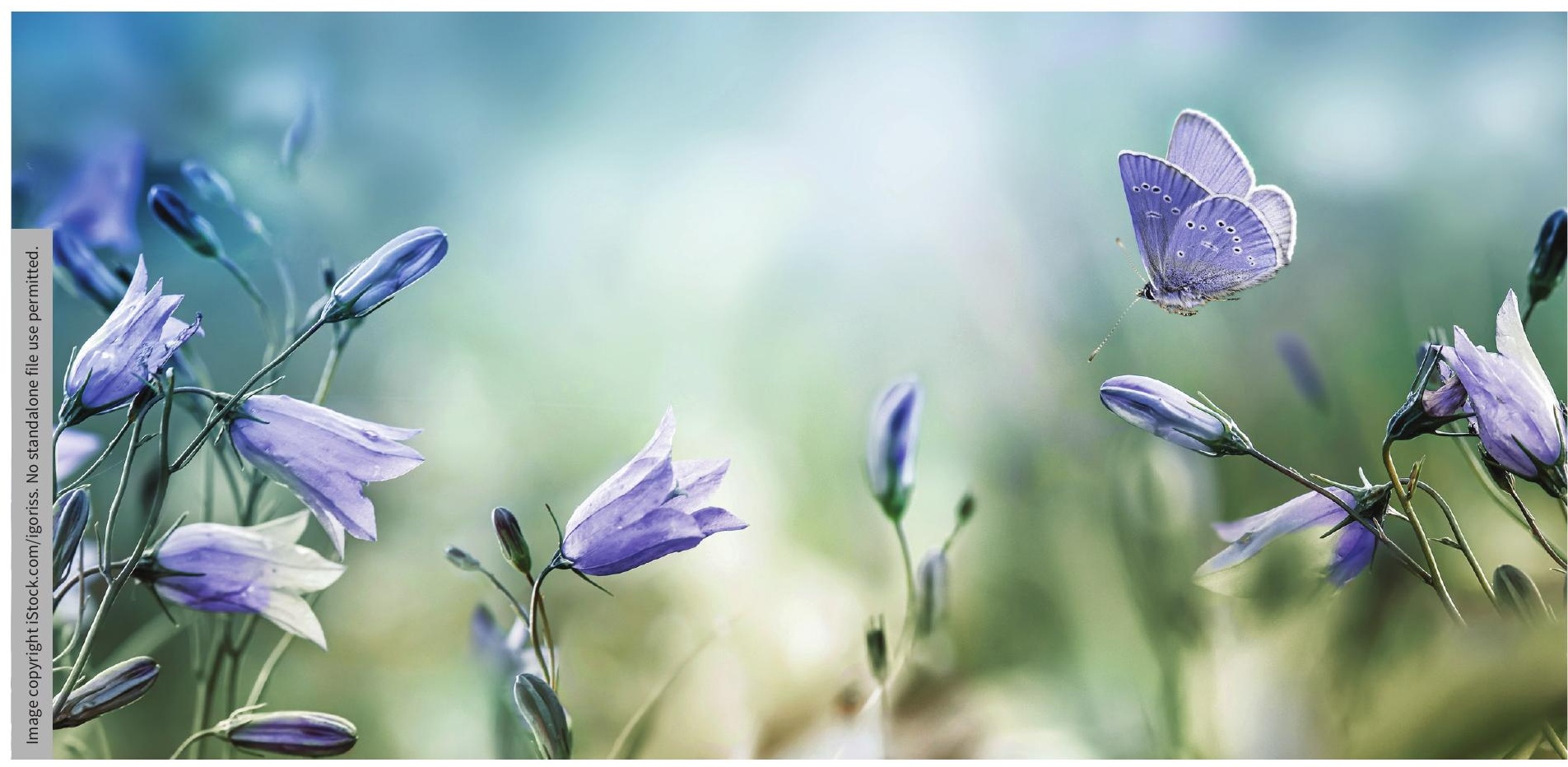

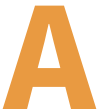

fter her diagnosis, I questioned myself constantly and agonized over the delayed mammogram. I felt so responsible. Sometimes I laid awake half the night, imagining her fear, thinking of her little daughter, her mother's reddened eyes.

She was in her twenties, with no family history or risk factors. The day she told me she had a heavy feeling in her breast, I could not feel a lump. Young and active, balancing a toddler on her hip, she wondered if it could be a pulled muscle.

Reassessing her at the next office visit several weeks later, I became extremely concerned to find a palpable mass. I felt off-balance, light-headed, filled with selfreproach as I ordered an urgent mammogram. How could I have missed this?

"She has a large malignant tumour," the radiologist said gravely on the phone. "I've asked her to go directly to your office." In shock, I realized I had about three minutes to prepare to tell her this devastating news in the middle of a busy morning. How could I tell her without her husband here to offer support? Without discussing this with oncology first, without booking some extra time for her at the end of the day? She arrived with her sister, and they were already very alarmed. I struggled to be calm and clear-headed. I don't remember exactly how I told her, but her grief that day haunts me.

For 10 years she battled through chemotherapy, radiation, a mastectomy then metastases to the bones and liver. Finally, she was admitted to the intensive care unit in a nearby city with an uncommon bowel complication. I drove there to see her one evening, so that plans could be made for her discharge home for palliative care.

A few days later, I visited her at home, where a hospital bed was set up in her kitchen. The walls were painted a soft orange, the colour of sunsets. I could picture a table in the space where her bed was now, with her family laughing and telling stories about their day.

As I looked into her sparkling brown eyes, I saw a fighting spirit worthy of a warrior princess. "I don't want to die," she whispered, as oxygen softly hissed and bubbled at her bedside.

I prayed for her to stay alive, because she was young and beautiful, because she had children, because it was so unfair - and because I was terrified by the realization that I couldn't save her. As her condition worsened, she suffered terribly, and I stopped praying for her to live longer. Instead, I prayed for less pain, less nausea, less fear.

She was no longer speaking when her father sat by her bed and looked up, his face drawn and pale. "I hate that she can't talk to me anymore," he said.

Her eyes fluttered open and she said clearly, "I love you Dad." 
Tears flowed as we watched her return to her shallow breathing. It was like she had crossed a bridge and we were left on the other side.

I remembered that her father had made an appointment with me shortly after her diagnosis, when he asked, "How could this happen?" His quiet words had stung like an accusation, increasing my remorse for being unable to assure him that his daughter could be healed.

I had felt terrible guilt for 10 years because of the delay in diagnosis, but during the last conversation we had before she died, she said, "Thank you for looking after me." Did she know how kind this was? It was the kindest gift I had ever received, and I did not feel worthy of it. I was in awe of her ability to hold on but then let go with such grace and compassion. I thought she was saying goodbye to me and at the same time, making sure I felt forgiven.

The call came from her husband in the early morning hours, after a night of howling wind and lightning flashes. Broken branches littered the dark country road as I drove to her house to pronounce her dead.

Medical equipment surrounded her oxygen mask and tubing, nutritional supplements on a bedside table, boxes of alcohol wipes and gauze, and the small, sealed package of a butterfly needle. How ironic that the tiny needles to inject morphine are called butterflies. As if the delicate beauty of a butterfly could possibly be associated with a young mother's pain.

Her sister smoothed the blankets around her as if she were laying a small child down for a nap. She wept as she gently pushed a strand of hair from her sister's forehead. Our eyes met and I believe we both felt relieved that she was finally free of surgeries and chemo, medicines and treatments, initially designed to cure, then to help, then finally just to buy some time. She looked serene as I folded her hands around the little stuffed turtle that was always on her bed. The house was quiet; her children slept peacefully upstairs.

When the funeral attendants wheeled her body silently out of the house, they had to unplug the large Christmas angel on the deck to get the stretcher by. The darkness seemed so final, until one of the men knelt and plugged it in again. Christmas Eve was 10 days away, although the yard was soft and wet with mud as I left. I remember thinking that it should be snowing, that she should be getting ready for Christmas with her kids.

Her death left me devastated. My inability to save her reminded me that this could happen again. I felt inadequate, like an imposter, unable to heal anyone - least of all myself. I saw my grief and sensitivity as a weakness, a failure to keep professional boundaries with the patients and families under my care, especially in a small town.

I drove to work that morning as the sun began to lighten the horizon, the road still wet and littered with broken branches. In the parking lot, I glanced in the rear-view mirror. My eyes were glazed with grief and fatigue. I thought of my day ahead and felt suddenly powerless. Powerless to recapture the idealism I had felt as a young doctor, powerless to find the time for my own self-reflection and healing. Although my compassion and sensitivity made me a better doctor, especially for those patients I was unable to heal, I recognized the need to direct some of that compassion back to myself.

\section{Sharon McCutcheon MD}

Sussex, NB

This article has been peer reviewed.

This is a true story. The patient's husband has given his consent for this story to be told.

Content licence: This is an Open Access article distributed in accordance with the terms of the Creative Commons Attribution (CC BY-NC-ND 4.0) licence, which permits use, distribution and reproduction in any medium, provided that the original publication is properly cited, the use is noncommercial (i.e., research or educational use), and no modifications or adaptations are made. See: https://creativecommons. org/licenses/by-nc-nd/4.0/ 